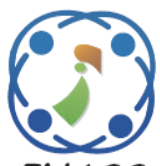

\title{
Dual Band Notched CPW Fed Printed Monopole Antenna for UWB Applications
}

\author{
Vutukuri Sarvani Duti Rekha ${ }^{1,2}$ \\ Boddapati Taraka Phani Madhav ${ }^{3 *}$ \\ Pokkunuri Pardhasaradhi ${ }^{3}$ \\ Yalavarthi Usha Devi ${ }^{3}$ \\ ${ }^{1}$ Department of Electronics and Communication Engineering, \\ Koneru Lakshmaiah Education Foundation, AP, India \\ ${ }^{2}$ Department of Electronics and Communication Engineering, \\ P V P Siddhartha Institute of Technology, Vijayawada, AP, India \\ ${ }^{3}$ Department of Electronics and Communication Engineering, \\ Koneru Lakshmaiah Education Foundation, AP, India \\ * Corresponding author's Email: btpmadhav@kluniversity.in
}

\begin{abstract}
A Coplanar waveguide (CPW) fed printed monopole antenna with dual notch band characteristics is proposed for Ultra wideband (UWB) applications. The Ultra wideband antenna operates from $2.48 \mathrm{GHz}$ to $18.35 \mathrm{GHz}$. Dual notch band is achieved by incorporating double H-slot structure in the radiating element. It achieved notch bands at $3.5 \mathrm{GHz}$ (WiMAX) and $8.3 \mathrm{GHz}$ (military/radar). The proposed antenna is investigated for the notch bands and operating band as well for various performance parameters like voltage standing wave ratio (VSWR), surface current distribution and far field radiation characteristics. It achieved a peak gain of $5.2 \mathrm{~dB}$ in the operating band. The proposed antenna is fabricated on fr 4 substrate of dimensions $37 \times 40 \times 1.6 \mathrm{~mm} 3$. By analysing the simulated and measured results of the proposed antenna it is observed that the proposed antenna is good for UWB applications by eliminating WiMAX and military/radar application interferences.
\end{abstract}

Keywords: Coplanar waveguide (CPW) fed, Dual notch band, Double H-slot, Printed monopole antenna, Ultra wideband (UWB) applications.

\section{Introduction}

Ultra wideband antenna has a vital role in the present wireless communication systems. UWB antennas have large communication capacity with high data rates and are low cost antennas. The advancements in the ultra-wideband technology enable high data transmission rate for indoor and outdoor communications with low power consumption. The simple hardware configurations make this ultra-wideband technology as unique advantageous solution over conventional narrow band technology. Nevertheless, the UWB system still facing different challenges like interference to WLAN operating in the IEEE WiMAX network 3.35-GHz (3.3-3.4 GHz), 3.5-GHz (3.4-3.6 GHz), 3.7-GHz (3.6-3.8 GHz) (5.725-5.85 GHz), WLAN $5.25-\mathrm{GHz}(5.15-5.35 \mathrm{GHz})$ and $5.75-\mathrm{GHz}(5.725-$ $5.825 \mathrm{GHz}$ ), IEEE INSAT/Super-Extended C-band, and $\mathrm{X}$-band 7.5-8.5 GHz operating bands.
Researchers are designing different antennas with multiband characteristics for compact and handheld devices for multi service systems.

Various band notched antennas were proposed and designed by different researchers for ultra wide band applications. Planar UWB antennas with notch band characteristics especially in WLAN, WiMAX and DSRC band are proposed by various authors [18]. Rahman M Proposed a CPW fed triple notch band UWB antenna with bandwidth enhancement [9]. Tunable and multi band notched antennas are proposed in [10-14] by researchers using SRR and CSRR. Reconfigurable UWB antennas with dual notches are proposed in $[15,17]$. UWB antennas with notch bands are proposed for IoT and wireless medical applications in $[16,18]$. Z. Li proposed [19] Vivaldi antenna with dual notch at $5.3-5.8 \mathrm{GHz}$ and 7.85-8.55 GHz. Triple band notched UWB antenna with CSRR and inverted U-slot is proposed 
in [20]. A monopole antenna with gap sleeve is proposed for UWB applications [21].

In this paper, a dual band notched antenna with super ultra-wide band characteristics is proposed. Section 2 gives the proposed antenna design iterations and geometrical specifications. Simulated results, parametric analysis and discussions of various antenna performance parameters are described in section 3. Antenna fabrication, prototype model and the experimental results are represented in section 4 and 5 respectively and comparison of the proposed UWB antenna with dual notch with other research works is also presented in Section 5. Section 6 gives the conclusion of the proposed dual band notched antenna and its simulated and measured performance.

\section{Antenna design}

Fig. 1 (a), iteration-1 shows the geometry of reference UWB antenna. It is based on a planar monopole structure with truncated rectangular patch and gap Sleeves. Ultra wideband characteristics are achieved by carefully designing the gap between monopole and the ground and coplanar waveguide (CPW) feed method is used to feed the antenna with 50-ohm impedance.

To conquer the surplus potential interference of existing narrow band systems with UWB antenna, notch band antennas are desired to be designed. Double U-slot is introduced in monopole structure to obtain notch band characteristics for the proposed UWB antenna. The geometry is represented in Fig. 1 (b) iteration 2. It achieved single notch band characteristics. By employing $\mathrm{H}$-slot and a pair of U-slots in monopole structure, dual notch bands are obtained through $3.2-3.9 \mathrm{GHz}$ (WiMAX) and 7.9$8.6 \mathrm{GHz}$ (military/radar applications) bands.

The geometry of the proposed dual notched band antenna along with its specifications are given in Fig. 1 (c) iteration 3. ANSYS HFSS simulation tool is used to design and optimize the proposed antenna. The proposed antenna is fabricated on a FR-4 substrate of dielectric constant 4.4 and thickness $1.6 \mathrm{~mm}$.

\section{Antenna design}

\subsection{VSWR characteristics}

Simulated VSWR characteristics of the proposed antenna iterations are plotted in Fig. 2. It is observed form these characteristics that iteration-1 has achieved super ultra wide band characteristics ranging from $2.4 \mathrm{GHz}$ to $18.35 \mathrm{GHz}$. By introducing double U-slots in truncated rectangular patch structure of the proposed UWB antenna in iteration2 , single notch is observed in VSWR characteristics from $4.0-4.78 \mathrm{GHz}$. Dual notches are observed in iteration-3 by employing a pair of $\mathrm{H}$-slot and U-slots in the monopole structure. Dual band notched characteristics are observed at $3.2-3.9 \mathrm{GHz}$ (WiMAX) and 7.9-8.6GHz.

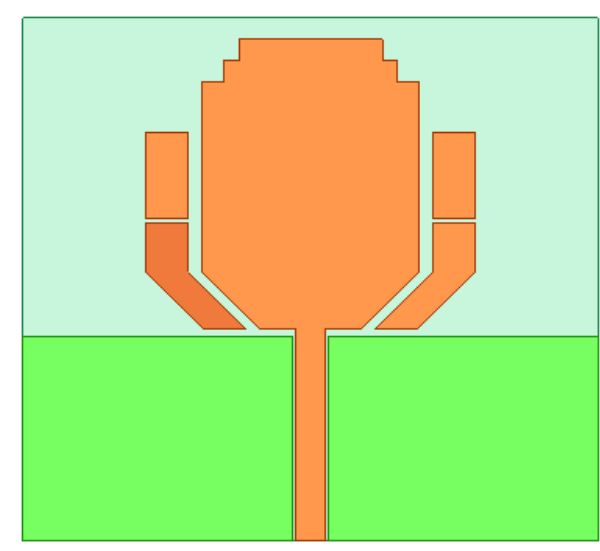

(a)

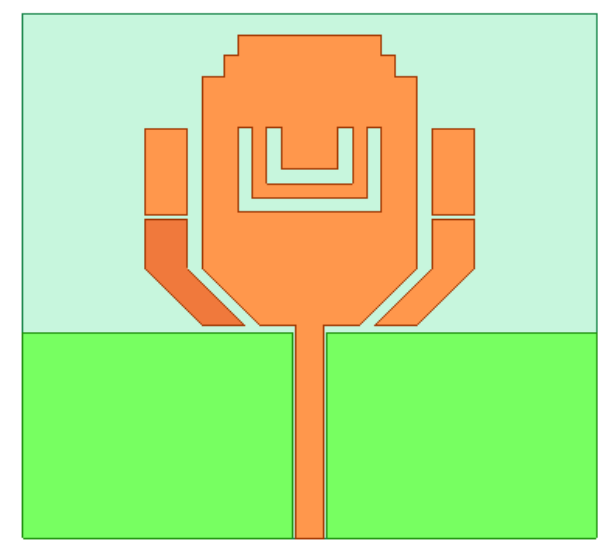

(b)

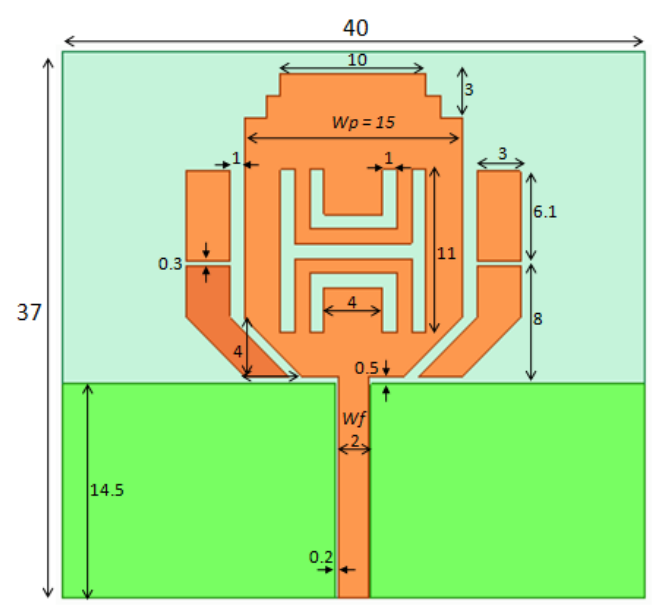

(c)

Figure. 1 Iterations of the proposed antenna: (a) iteration 1 , (b) iteration 2, and (c) iteration 3 


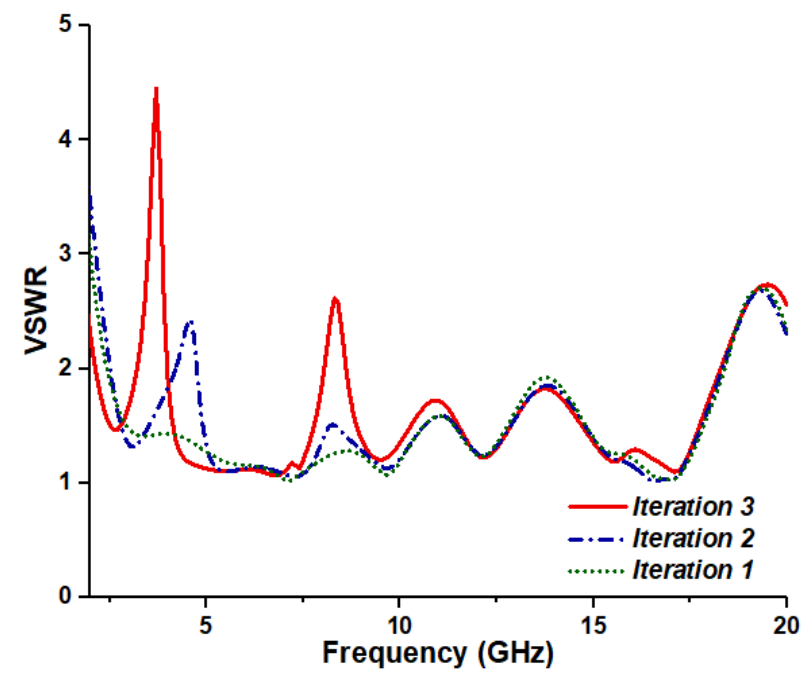

Figure. 2 Simulated VSWR characteristics of the proposed antenna iterations

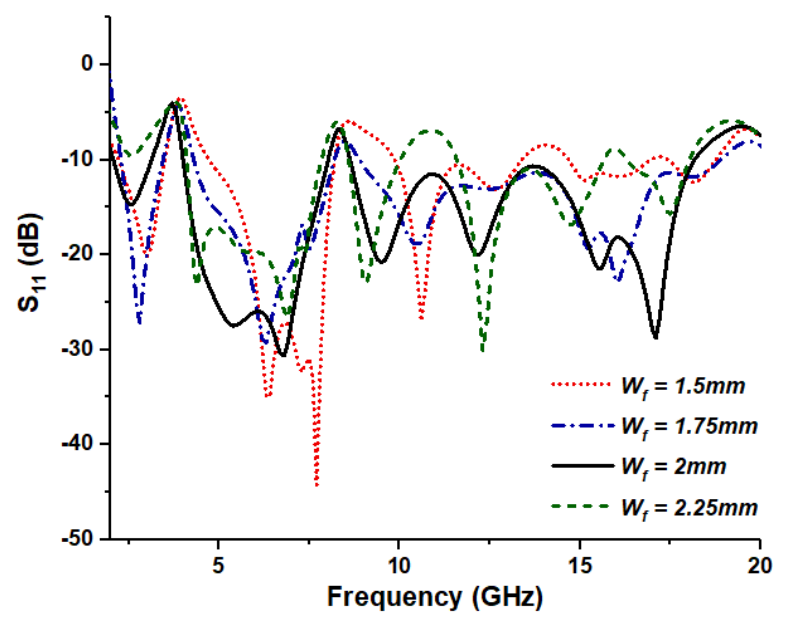

(a)

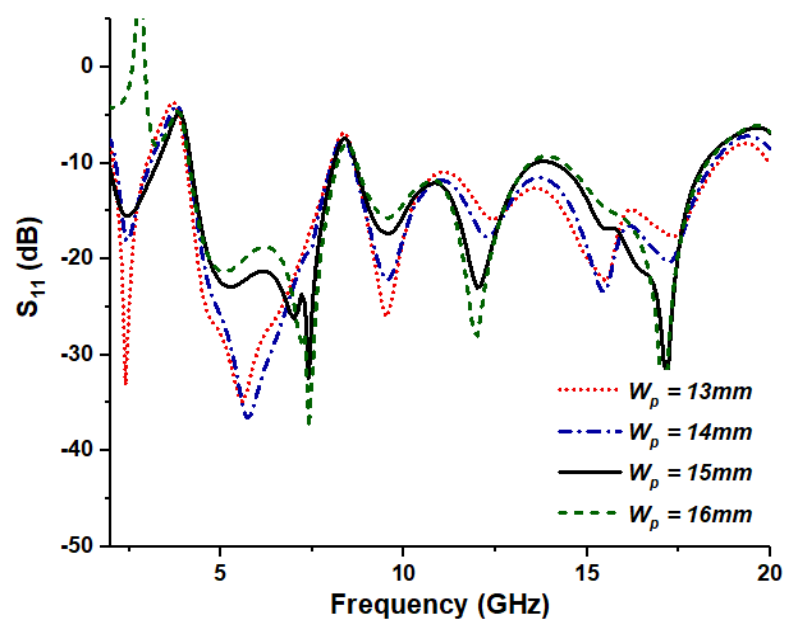

(b)

Figure. 3 Simulated $S_{11}$ characteristics of the proposed antenna for: (a) variations in $\mathrm{W}_{\mathrm{f}}$ and (b) variations in $\mathrm{W}_{\mathrm{p}}$

\subsection{Parametric analysis}

To optimize the proposed antenna parameters and performance, parametric analysis is carried out for the proposed dual band notch antenna. The parameters, feed width (Wf) and width of the truncated rectangular patch $(\mathrm{Wp})$ are analyzed for different values. Fig. 3 (a) represents the parametric analysis with respect to Wf in-terms of S11 characteristics. Wf is varied from $1.5 \mathrm{~mm}$ to $2.5 \mathrm{~mm}$ with a step size of $0.25 \mathrm{~mm}$. It is observed that for $\mathrm{Wf}=2 \mathrm{~mm}$, the proposed antenna exhibits good notch band characteristics for WiMAX and Military/radar applications. S11 characteristics for the variation of $\mathrm{Wp}$ from $13 \mathrm{~mm}$ to $16 \mathrm{~mm}$ with a step size of $1 \mathrm{~mm}$ are plotted in Fig. 3 (b). Form these characteristics, it can be viewed that for $\mathrm{Wp}=$ $15 \mathrm{~mm}$, the proposed antenna has good UWB characteristics with dual notches for WiMAX and military/radar applications.

\subsection{Surface current distribution}

Surface current distribution of the proposed dual band notch antenna at notch frequencies $3.6 \mathrm{GHz}$, $8.3 \mathrm{GHz}$ and at two operating frequencies $5.8 \mathrm{GHz}$, $10 \mathrm{GHz}$ are represented in Figs. 4 (a), (b), (c), and (d) respectively. The current distribution at notch frequencies is very less and the current distribution for operating frequencies is high and it is more concentrated in radiating element feed line and the corners of truncated rectangular patch.

\section{Fabricated antenna}

The proposed CPW fed UWB antenna with dual bands notched is fabricated on FR-4 substrate of dimensions $37 \times 40 \mathrm{~mm}^{2}$, thickness $1.6 \mathrm{~mm}$ and dielectric constant of 4.4 .

The fabricated proposed antenna is presented in Fig. 5 (a) and its experimental set-up with VNA for measuring antenna performance parameters is represented in Fig. 5 (b).

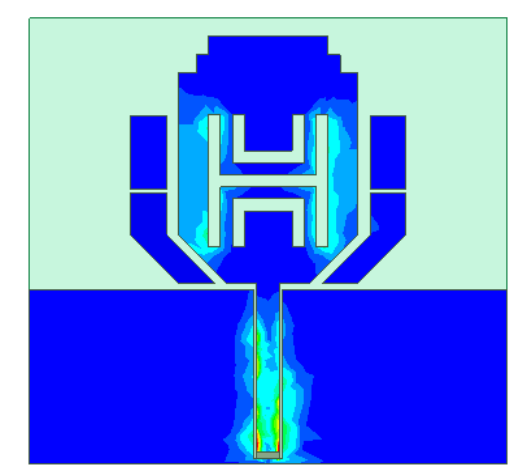

(a) 


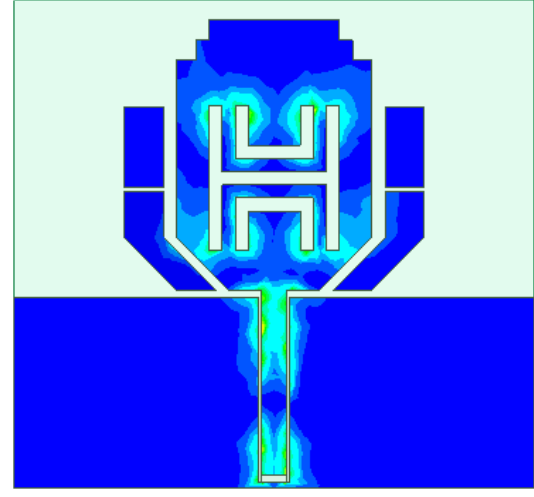

(b)

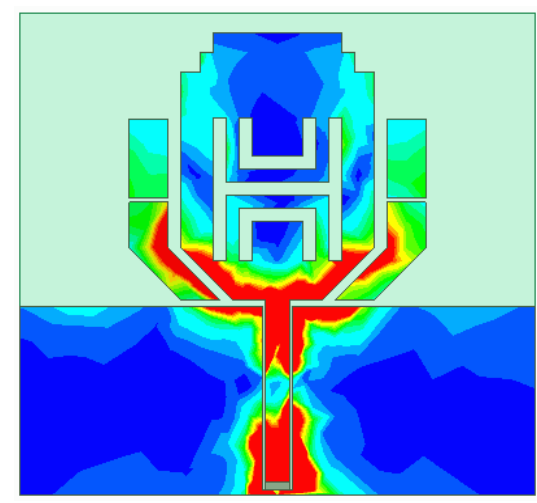

(c)

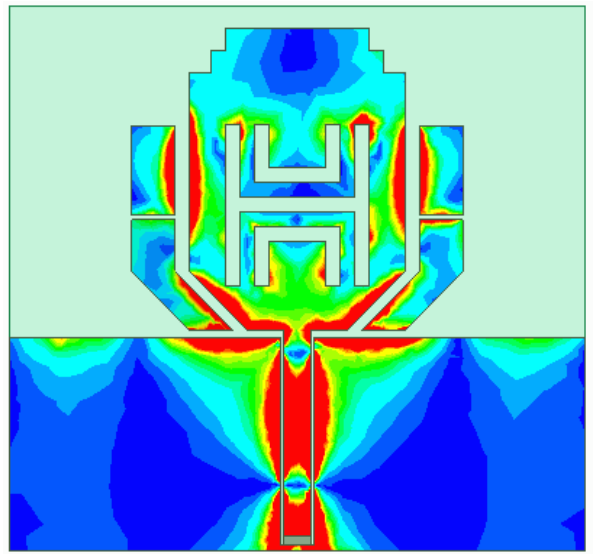

(d)

Figure. 4 Surface current distribution of the proposed antenna: (a) $3.6 \mathrm{GHz}$, (b) $8.3 \mathrm{GHz}$, (c) $5.8 \mathrm{GHz}$, and (d) $10 \mathrm{GHz}$

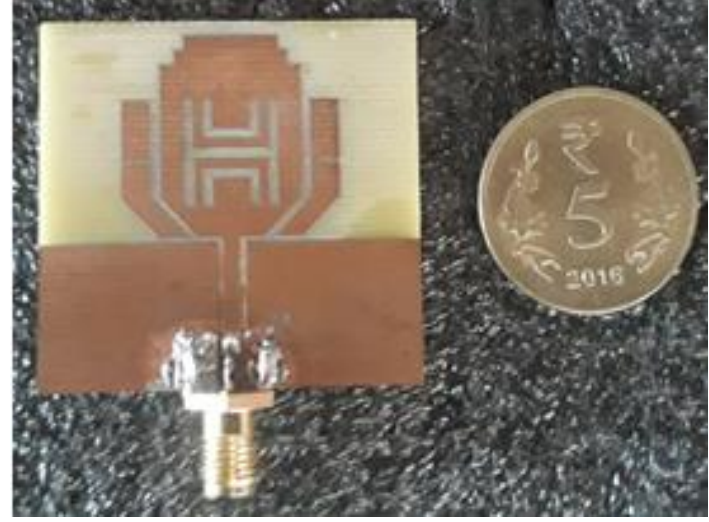

(a)

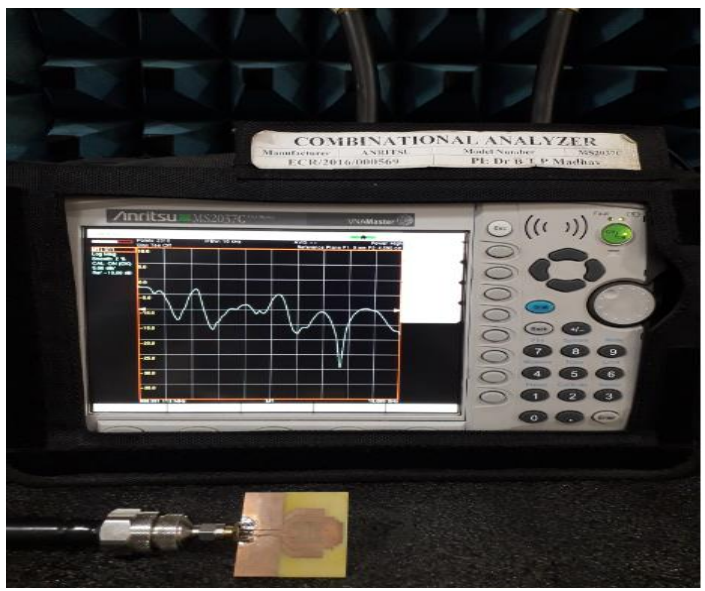

(b)

Figure. 5 Fabricated proposed antenna and its experimental set-up: (a) fabricated antenna and (b) Experimental set-up with VNA

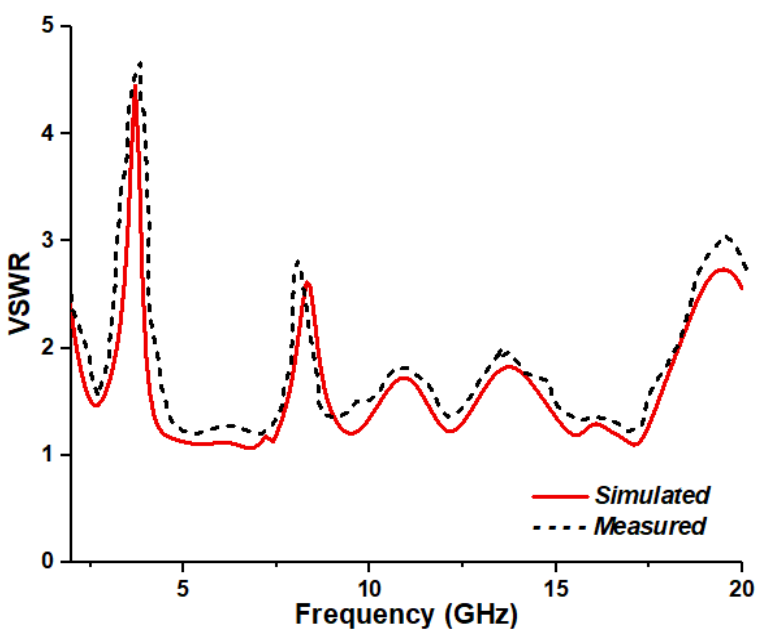

Figure. 6 Simulated and measured VSWR characteristics of the proposed antenna

\section{Experimental results}

Fig. 6 plots the simulated and measured VSWR characteristics of the proposed UWB antenna with dual band notched. As observed in the figure, 
measured values are close to simulated values and notches are observed at $3.65 \mathrm{GHz}$ and $8.2 \mathrm{GHz}$.

Fig. 7 (a) illustrates 3D gain plot of the proposed UWB antenna at $10 \mathrm{GHz}$ resonant frequency. It achieved directional radiation and the plane of radiation is along the plane of antenna. Figs. 7 (b), (c), (d), and (e) represent the simulated and measured radiation patterns (co-polarization and cross polarization) of proposed dual notch antenna for two operating frequencies $(10 \mathrm{GHz}$ and $5.8 \mathrm{GHz})$ and for the two notched band $(3.6 \mathrm{GHz}$ and $8.3 \mathrm{GHz})$. At $10 \mathrm{GHz}$, the proposed antenna exhibits directional patterns with a maximum of $4.8 \mathrm{~dB}$ gain. At $5.8 \mathrm{GHz}$, the patterns are dipole like directional and achieved valid gain. At operating frequencies, the proposed antenna maintains good acceptable difference between co-polarization and cross polarization patterns. At notch frequencies, $3.6 \mathrm{GHz}$ and $8.3 \mathrm{GHz}$ it can be observed that there is not much difference between co-polarization and cross polarization patterns. Hence, it suppresses the dual notch frequencies.

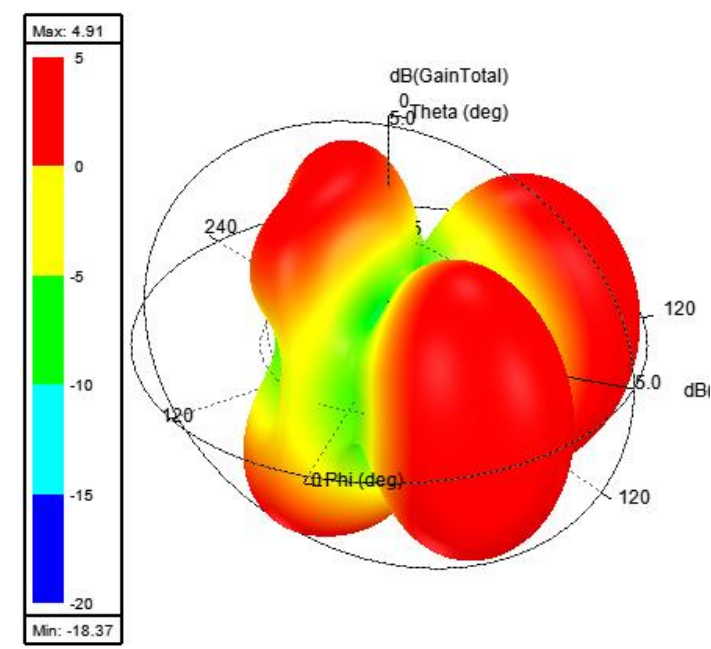

(a)

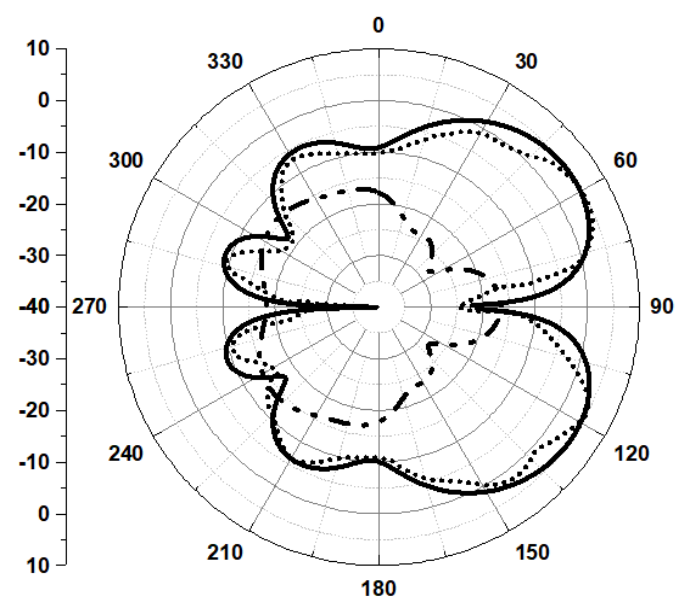

(b)

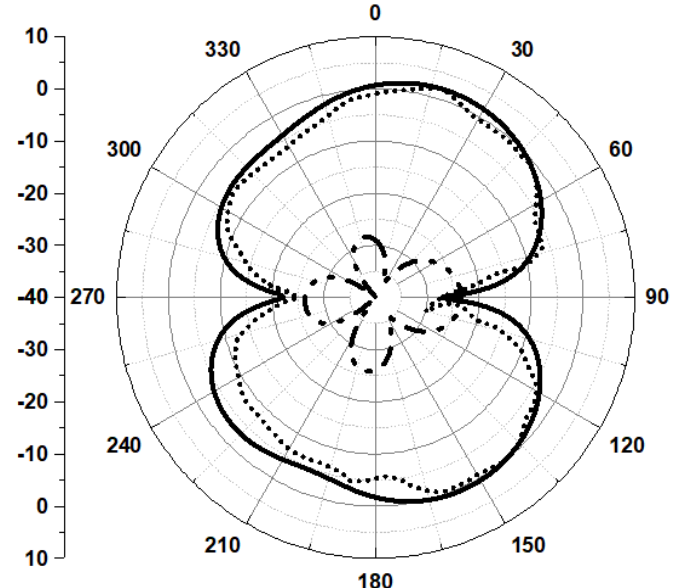

(c)

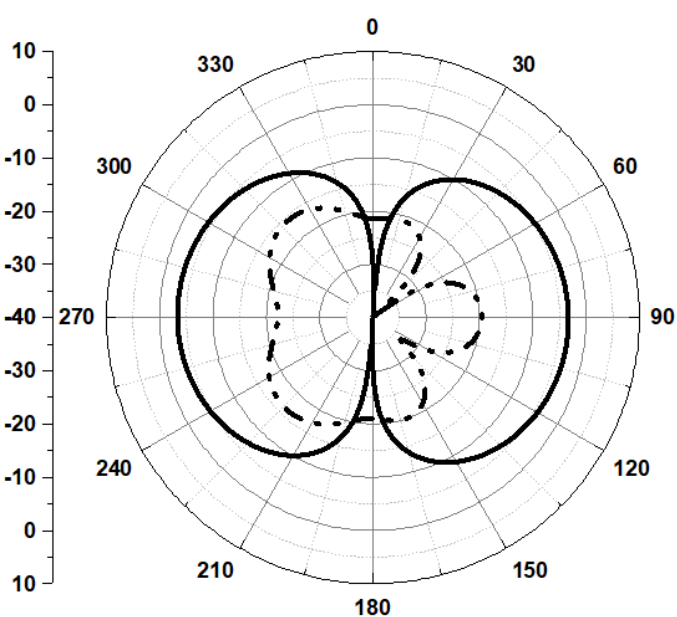

(d)

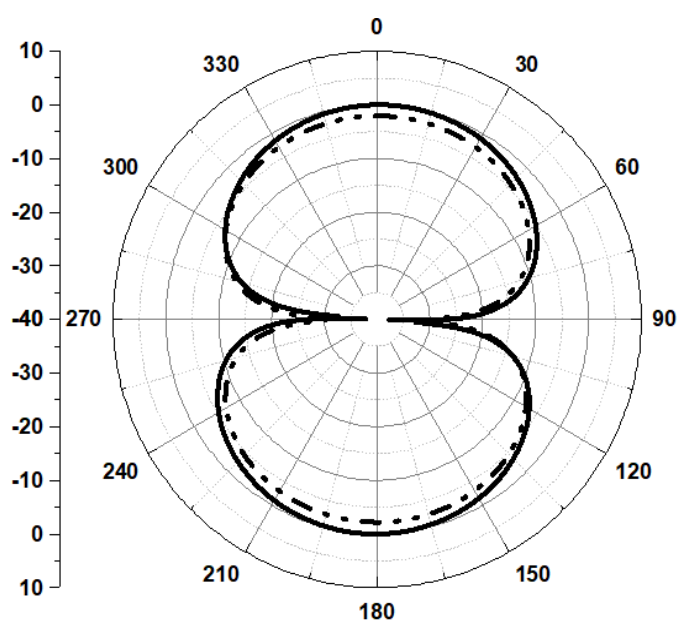

(e)

\section{- Simulated Co-polarization}

- - Simulated Cross polarization

\section{.... Measured Co-polarization}

Figure. 7 Radiation patterns of proposed antenna: (a) $3 \mathrm{D}$ gain plot of proposed antenna at $10 \mathrm{GHz}$, (b) theta $=90 \mathrm{deg}$ at $10 \mathrm{GHz},(\mathrm{c})$ theta $=90 \mathrm{deg}$ at $5.8 \mathrm{GHz},(\mathrm{d})$ theta $=90 \mathrm{deg}$ at $8.3 \mathrm{GHz}$, and (e) theta $=90 \mathrm{deg}$ at $3.6 \mathrm{GHz}$ 
Table 1. Comparison of parameters of the proposed antenna

\begin{tabular}{|c|c|c|c|c|c|}
\hline Author, [Ref. No.] & $\begin{array}{c}\text { Operating Band } \\
(\mathrm{GHz})\end{array}$ & $\begin{array}{c}\text { Bandwidth } \\
(\mathrm{GHz})\end{array}$ & $\begin{array}{c}\text { Notch Bands } \\
(\mathrm{GHz})\end{array}$ & $\begin{array}{c}\text { Gain }(\mathrm{dB}) \\
\text { Efficiency }(\%)\end{array}$ \\
\hline M. Abedian [7] & $3-13$ & 10 & $3.22-4.064 .84-5.96$ & 4.8 & 96 \\
\hline Le Kang [8] & $3.08-11.8$ & 7.72 & $5.03-5.97$ & 3.6 & NA \\
\hline Z. Li, C. Yin [19] & $2.9-11.6$ & 8.7 & $5.3-5.8,7.8-8.5$ & 6 & 96.2 \\
\hline Proposed & $2.48-18.35$ & 15.87 & $3.2-3.9,7.9-8.6$ & 5.2 & \\
\hline
\end{tabular}

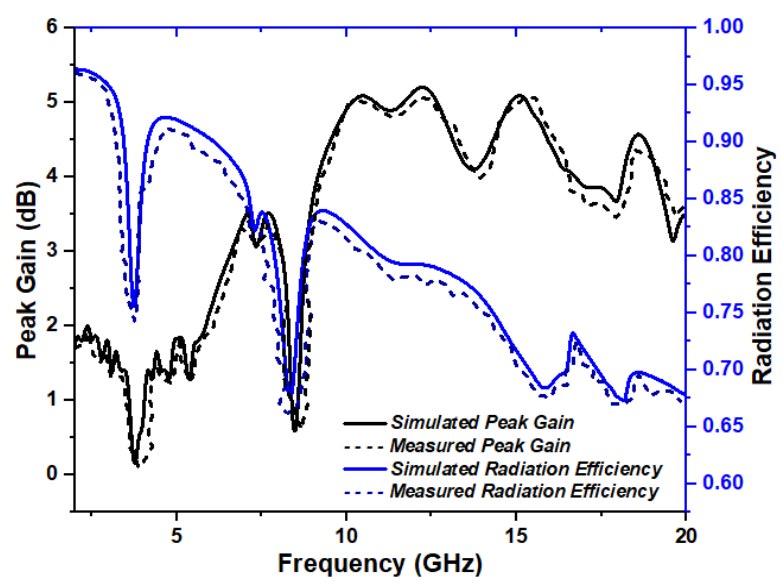

Figure. 8 Gain and radiation efficiency characteristics of the proposed antenna

Simulate and measured gain $(\mathrm{dB})$ vs frequency $(\mathrm{GHz})$ and radiation efficiency vs frequency $(\mathrm{GHz})$ characteristics are plotted in Fig. 8. Simulated peak gain is $5.2 \mathrm{~dB}$ at $12.2 \mathrm{GHz}$ and measured peak gain is $5.1 \mathrm{~dB}$ at $12.2 \mathrm{GHz}$. The simulated maximum radiation efficiency is $96.2 \%$ obtained at $2.4 \mathrm{GHz}$. It can be observed that simulated and measured values are in good agreement and the gain, radiation efficiency values are less at notch frequencies compared to operating band values.

To validate the proposed dual notched UWB antenna, the parameters gain, notch bands, operating band, bandwidth and radiation efficiency of the proposed model are compared with existing UWB notch antenna models in Table 1.

As mentioned in Table 1, the proposed dual notched band UWB antenna has better performance parameters. It achieved super ultra wide band with reasonably good gain and radiation efficiency.

\section{Conclusions}

In this paper, CPW fed super UWB antenna operating from $2.4-18.35 \mathrm{GHz}$ is presented with dual notch at $3.5 \mathrm{GHz}$ (WiMAX) and $8.3 \mathrm{GHz}$ (military/radar applications bands). Dual notch bands are achieved with the employment of a pair of $\mathrm{H}$-slot and U-slots in monopole structure of the proposed antenna. Simulated and measured values of various antenna performance parameters like VSWR characteristics, surface current distribution, far-field radiation characteristics are investigated. VSWR values are between 2 and 1 in the entire operating range except at notch frequencies. At $3.6 \mathrm{GHz}$ VSWR value is 4.5 and at $8.3 \mathrm{GHz}$ it is 2.8 . The proposed antenna achieved a peak gain of $5.2 \mathrm{~dB}$ and maximum radiation efficiency of $96.2 \%$. The radiation patterns are directional, and the proposed antenna radiates maximum for $60^{\circ}$ and $120^{\circ}$ at $10 \mathrm{GHz}$. The analysis of the proposed antenna suggests it as a good candidate for UWB applications with the provision of WiMAX and military/radar applications band rejection. Further work can be carried out with reconfigurable MIMO antenna for UWB applications.

\section{Acknowledgments}

The authors deeply express their gratitude to CSIRSRF-09//1068(0002)/2018-EMR-I and SERBEEQ/2016/000604 and ECR/2016/000569 for their technical support.

\section{References}

[1] X. L. Liu, Y. Z. Yin, P. A. Liu, J.H. Wang, and B. Xu, "A CPW-fed dual band-notched UWB antenna with a pair of bended dual-L-shape parasitic branches", Progress in Electromagnetics Research, Vol.136, pp.623634, 2013.

[2] R. Azim and M. T. Islam, "Compact planar UWB antenna with band notch characteristics for WLAN and DSRC", Progress in Electromagnetics Research, Vol.133, pp.391406, 2013.

[3] P. Lotfi, M. Azarmanesh, and S. Soltani, "Rotatable dual band-notched UWB/triple-band WLAN reconfigurable antenna", IEEE Antennas and Wireless Propagation Letters, Vol.12, pp.104-107, 2013. 
[4] S. R. Emadian, C. Ghobadi, J. Nourinia, M.H. Mirmozafari, and J. Pourahmadazar, "Bandwidth enhancement of CPW-fed circlelike slot antenna with dual band-notched characteristic", IEEE Antennas and Wireless Propagation Letters, Vol. 11, pp.543-546, 2012.

[5] S. Yadav, A. K. Gautam, and B. K. Kanaujia, "Design of dual band-notched lamp-shaped antenna with UWB characteristics", International Journal of Microwave and Wireless Technology, Vol.9, pp.395-402, 2015.

[6] A. M. Prasanth, S. Prasanth, B. M. S Krishna, and D. Manikantha, "Analysis of Defected Ground Structure Notched Monopole Antenna", ARPN Journal of Engineering and Applied Sciences, Vol. 10, No. 2, pp.747-752, 2015.

[7] M. Abedian, S. K. A. Rahim, Sh. Danesh, S. Hakimi, L. Y. Cheong, and M. H. Jamaluddin, "Novel Design of Compact UWB Dielectric Resonator Antenna With Dual-Band-Rejection Characteristics for WiMAX/WLAN Bands", IEEE Antennas And Wireless Propagation Letters, Vol. 14, pp.245-248, 2015.

[8] L. Kang, H. Li, X. Wang, and X. Shi, "Compact Offset Microstrip-Fed MIMO Antenna for Band-Notched UWB Applications", IEEE Antennas and Wireless Propagation Letters, Vol. 14, pp.1754-1757, 2015.

[9] M. U. Rahman, "CPW fed miniaturized UWB tri-notch antenna with bandwidth enhancement", Advances in Electrical Engineering, Vol.2016, pp.1-7, 2016.

[10] A. V. Krishna, "Planar Switchable Notch Band Antenna with DGS for UWB Applications", In: Proc. of 2nd International Conference on Micro-Electronics, Electromagnetics and Telecommunications, Lecture Notes in Electrical Engineering, pp.509-518, 2017.

[11] K. Murthy, K. Umakantham, and K. S. Murthy, "Reconfigurable Notch Band Monopole Slot Antenna for WLAN/IEEE-802.11n Applications", International Journal of Intelligent Engineering and Systems, Vol.10, No.6, pp.166-173, 2017.

[12] M. Rahman, D. S. Ko, and J. D. Park, "A Compact Multiple Notched Ultra-Wide Band Antenna with an Analysis of the CSRR-TOCSRR Coupling for Portable UWB Applications", Sensors, Vol. 17, No.10, pp.1-13, 2017.

[13] A. Ammar, Z. Zakaria, N. A. Shairi, I. Mohd Ibrahim, and S. Ahmed, "A Novel Reconfigurable UWB Filtering-Antenna with
Dual Sharp Band Notches Using Double Split Ring Resonators", Progress in Electromagnetics Research C, Vol. 79, pp.185198, 2017.

[14] M. V. Rao and T. Anilkumar, "Conformal Band Notched Circular Monopole Antenna Loaded with Split Ring Resonator", Wireless Personal Communications, Vol.103, No.3, pp.1965-1976, 2018.

[15] M. V. Lakshmi and P. Pardhasaradhi, "Circular Monopole Reconfigurable Antenna with Notch Band Filter Characteristics", Journal of Engineering Science and Technology Review, Vol.11, No.5, pp.139-143, 2018.

[16] M. Rahman and J. D. Park, "The Smallest Form Factor UWB Antenna with Quintuple Rejection Bands for IoT Applications Utilizing RSRR and RCSRR", Sensors, Vol.18, No.3, pp.1-16, 2018.

[17] M. Nejatijahromi, M. Rahman, and M. Naghshvarianjahromi, "Continuously Tunable WiMAX Band-Notched UWB Antenna with Fixed WLAN Notched Band", Progress in Electromagnetics Research Letters, Vol.75, pp. 97-103, 2018.

[18] K. P. Srinivas and H. Khan, "A CPW fed Dual Band Notched UWB Antenna for Wireless Medical Applications", Indian Journal of Public Health Research \& Development, Vol.9, No.6, pp.306-310, 2018

[19] Z. Li, C. Yin, and X. Zhu, "Compact UWB MIMO Vivaldi Antenna with Dual BandNotched Characteristics", IEEE Access, Vol.7, pp.38696-38701, 2019.

[20] A. Yadav, M. D. Sharma, and R. P. Yadav, "A CPW-Fed CSRR and Inverted U Slot Loaded Triple Band Notched UWB Antenna", Progress in Electromagnetics Research C, Vol. 89, pp.221-231, 2019.

[21] S. W. Kang and T. S. Chang, "Design of A Planar Monopole Antenna with Gap Sleeve By Half Cutting Method", International Journal of Microwave and Optical Technology, Vol.12, No.4, pp.274-278, July 2017. 